\title{
Choroid Plexus of the Fourth Ventricle: Review and Anatomic Study Highlighting Anatomical Variations
}

\author{
R. Shane Tubbs ${ }^{1}$, Mohammadali M. Shoja ${ }^{2}$, Anjali Aggarwal ${ }^{3}$, Tulika Gupta ${ }^{3}$, Marios Loukas ${ }^{4}$, \\ Daisy Sahni ${ }^{3}$, Shaheryar F. Ansari ${ }^{5}$, Aaron A. Cohen-Gadol ${ }^{5}$
}

${ }^{1}$ Seattle Science Foundation, Seattle, WA, USA

2 Pediatric Neurosurgery, Children's of Alabama, Birmingham, AL, USA

${ }^{3}$ Department of Anatomy, Postgraduate Institute of Medical Education and Research, Chandigarh India

${ }^{4}$ Department of Anatomical Sciences, St. George’s University, Grenada

${ }^{5}$ Goodman Campbell Brain and Spine, Indiana University Department of Neurological Surgery, Indianapolis, IN, USA

\section{Corresponding Author:}

Aaron A. Cohen-Gadol, MD, MSc

Goodman Campbell Brain and Spine

Indiana University, Department of Neurosurgery

$355 \mathrm{~W} 16^{\text {th }}$ St, Suite 5100

Indianapolis, IN 46202

E-mail: acohenmd@gmail.com

Phone: 317-362-8760

Fax: 317-924-8472

This is the author's manuscript of the article published in final edited form as:

Tubbs, R. S., Shoja, M. M., Aggarwal, A., Gupta, T., Loukas, M., Sahni, D., ... Cohen-Gadol, A. A. (2016). Choroid plexus of the fourth ventricle: Review and anatomic study highlighting anatomical variations. Journal of Clinical Neuroscience, 26, 79-83. http://dx.doi.org/10.1016/j.jocn.2015.10.006 


\begin{abstract}
Relatively few studies have been performed that comment on the morphology of the choroid plexus of the fourth ventricle. With this tissue's importance as a landmark on imaging and during surgical intervention of the fourth ventricle, the authors performed a cadaveric study to better characterize this important structure. The choroid plexus of the fourth ventricle of sixty formalin fixed adult human brains was observed and measured. The horizontal distance from the midline to the lateral most point of the protruding tip of the horizontal limbs was measured. In the majority of the sixty brain specimens, right and left horizontal limbs of the choroid plexus were seen extending from the midline and protruding out of their respective lateral apertures of the fourth ventricle and into the subarachnoid space. However, on 3.3\% of sides, we found absence of an extension into the foramen of Luschka and in one specimen, this lack of extension into the foramen of Luschka was bilateral. On two sides, there was discontinuity between the midline choroid plexus and the tuft of choroid just outside the foramen of Luschka. For specimens in which choroid plexus did protrude through the foramen of Luschka (96.7\%), these tufts were located anterior to the flocculus and inferolateral to the facial/vestibulocochlear nerve complex and posterosuperior to the glossopharyngeal/vagal/accessory complex. A thorough understanding of the normal and variant anatomy of the fourth ventricular choroid plexus is necessary for those who operate in or interpret imaging of this region.
\end{abstract}

Keywords: anatomy; posterior cranial fossa; neurosurgery; neuroimaging; cerebrospinal fluid

\title{
Introduction
}

Surgically and pathologically, knowledge of the anatomy of the choroid plexus is important. This tissue is composed of two inverted, L-shaped, highly branching vascular tufts, which hang from the tela choroidea inferiorly and project into the cavity of the fourth ventricle 
where they are separated from the true cavity by the epithelial lining of the roof. Furthermore, the two ends of the plexus extend beyond the fourth ventricle into the cerebellopontine angle proximally and cerebellomedullary fissure distally. The three-dimensional anatomy and the relationships of this choroid plexus are complex owing to the intricate morphology of the fourth ventricle, cerebellomedullary fissure and cerebellopontine angle.

The choroid plexus of the fourth ventricle is a landmark structure during neurosurgical approaches and is sometimes seen on neuroimaging (Figs. 1-3). This tissue is used as a landmark structure during retrosigmoid approaches for auditory brainstem implantation [2]. However, few anatomical studies have been performed on this structure with almost none making comments regarding its anatomical variations. Therefore, the present review and anatomical study were conducted to better understand this structure of the fourth ventricle.

\section{Material and Methods}

The choroid plexus of the fourth ventricle of sixty formalin fixed adult human brains was studied. The fourth ventricle was opened and the choroid plexus identified. The horizontal distance from the midline to the lateral most point of the protruding tip of the horizontal limbs was measured. To measure the length of lateral limbs, a thread was placed along the horizontal limbs. The junction of the vertical and horizontal limbs as well as the end of the horizontal limbs was marked on the thread. The length of this marked segment of thread was then measured. All measurements were performed with a digital caliper with a precision of $0.02 \mathrm{~mm}$ (Mitutoyo, Japan). Statistical analysis was made using Statistica for Windows with significance set at $\mathrm{p}<0.05$.

\section{Results}

In the majority of the sixty brain specimens, right and left horizontal limbs of the choroid plexus were seen extending from the midline and protruding out of their respective lateral apertures of the fourth ventricle and into the subarachnoid space (Fig. 4). The mean distance of the lateral most point of the protruding tip of right and left horizontal limbs from the midline was 18.15mm (6.03-25.22 mm) and $7.96 \mathrm{~mm}(12.33-24.05 \mathrm{~mm})$, respectively with a combined mean

of $18.36 \mathrm{~mm}$ (12.77-24.67 mm). Paired t test showed no significant difference between right and left sides ( $\mathrm{p}>0.05)$. After exposing the choroid plexus, the mean length of the right horizontal 
limb was $25.43 \mathrm{~mm}$ (range 18.36-32.34 mm). The average length of the left horizontal limb was $22.94 \mathrm{~mm}$ (range 18.46-28.70 mm). The mean length of the right limb was greater than the left limb. A paired t test was applied. The length of the right and left horizontal limbs was found to differ significantly (p value $<0.001$ ). On four sides (3.3\%), we found absence of the extension into the foramen of Luschka (Fig. 5) and in one specimen, this lack of extension into the foramen of Luschka was bilateral (Fig. 6). On 2 sides (1.7\%) we observed a disconnection between the medial and lateral extensions of the choroid plexus (Fig. 7). For choroid plexus that did protrude through the foramen of Luschka (96.7\%), these tufts were located anterior to the flocculus and inferolateral to the facial/vestibulocochlear nerve complex and posterosuperior to the glossopharyngeal/vagal/accessory complex.

\section{Discussion}

Embryology

During development of the fourth ventricle, a transverse fold, the plica choroidea, appears. This structure begins in the midline and subsequent smaller folds grow from its edges. With continued growth of the hindbrain, the now choroid plexus, which begins in an extraventricular location, increases in width [9]. Interestingly, this extraventricular location may be maintained in the Chiari II malformation [18]. At the $7^{\text {th }}$ week of development, alterations in the roof of the rhombencephalon are important in the development of cerebrospinal fluid containing chambers within the brain. During this time, the mesoderm dorsal to the rhombencephalon is vascularized, and this is followed by infolding of the choroid plexus of the future fourth ventricle and division of the roof of the rhombencephalon into cranial and caudal parts. The structure of the tela choroidea inferior is composed of a duplicated layer of pia mater brought together by opposition of the inferior surface of the cerebellum to the dorsal surface of the developing medulla oblongata. At stage 19, choroid villi are seen in the fourth ventricle, and a mesencephalic evagination is detectable [11].

Histology 
Histologically, the choroid plexus is a villous structure composed of highly branching tufts of blood vessels in a collagenous stroma covered by cuboidal or columnar epithelial cells overlying a basal lamina. The vascular tufts are thin-walled, large and fenestrated (sinusoid), and epithelial cells contain long bulbous microvilli on the luminal surface. The tela choroidea inferior is formed by reduplication of pia mater by an arachnoid layer carrying a plexus of small blood vessels [8]. The epithelial cells covering the choroid plexus are derived from the ependymal lining of the ventricles.

\section{Anatomy}

The tela choroidea inferior (of the fourth ventricle) forms the roof of the lower half of the fourth ventricle. The tela is devoid of an arachnoid component. Above (in front of) the foramen of Magendie, the branches of the posterior inferior cerebellar artery within the tela choroidea inferior invaginate the epithelial lining of the tela to form two paramedian, linear longitudinal strands (choroid plexus of the fourth ventricle), projecting into the fourth ventricular cavity. The vessels of the paramedian strands communicate proximally at the base of the tela below and the inferior medullary velum and then run transversely and laterally to pass behind the restiform bodies and evaginate through the tela. The lateral prolongations of the choroid plexus, which are covered by the epithelial remnants of the tela (accompanied by the prolongation of the lingula), form two "grape-shaped" or "cauliflower-like" masses [14]. These tufts of choroid plexus protruding through the foramina of Luschka are referred to as Bochdalek's flower baskets (Blumenkörbchen). Some [6] have also referred to these lateral most extensions as "cornucopia."

\section{Anatomical Variations}

Variations of the normal morphology of the choroid plexus of the fourth ventricle have been rarely reported. Although the presence or absence of calcified choroid plexus or the shape of the distal extension through the lateral apertures has been mentioned in the literature (see below), other details of this structure's variations are lacking in the literature. In the present cadaveric study, on two sides (1.7\%), we observed a disconnection between the medial and lateral extensions of the choroid plexus (Fig. 7). On four sides (3.3\%), we found absence of extension into the foramen of Luschka (Fig. 5) and in one specimen, this lack of extension into the foramina of Luschka was bilateral (Fig. 6). 


\section{Topography}

The topography and relationships of the choroid plexus of the fourth ventricle are important to neuroradiologists and neurosurgeons (Table 1). The lateral segment of the choroid plexus is closely related to the flocculus. Matsushima et al. [11] divided the choroid plexus into two topographically-related medial and lateral segments, each further subdivided into two parts, collectively constituting four parts, namely, caudal or tonsilar, rostral or nodular, medial or peduncular part, and lateral or floccular parts. The medial segments are located sagittally at each side of the midline of the inferior part of the roof and extends from the level of the nodule (which forms the central area at the most rostral part of the inferior half of the roof) to the caudal vermis through the foramen of Magendie. The lateral segment extends transversely and laterally from the rostral end of the medial segment along the telovelar junction (line of attachment between tela choroidea inferior and inferior medullary velum) and passes through the lateral recess and foramen of Luschka to project into the cerebellopontine angle below the flocculus [3]. The nodulus is partly covered by the choroid plexus. The medial horizontal segments projects ventrally and slightly superiorly, overlapping the inferior medullary velum [6]. The lateral most tufts project outwards between the roots of the vestibulocochlear nerve superiorly and the glossopharyngeal nerve inferiorly. Ventrally, the lower surface of the tufts is crossed by the roots of the glossopharyngeal nerves and upper roots of the vagus nerve and this relationship has been used as an anatomical landmark for identifying these nerves [13,16,17]. The caudal ends of the choroid plexus attenuate at the level of the foramen of Magendie, and the epithelial roof from which they originate is stretched backward in contact with the undersurface of the cerebellum [14].

\section{Vasculature}

Matsushima et al. [11] noted that the anterior inferior cerebellar artery (AICA) commonly supplies the lateral two-third of the lateral segment of the choroid plexus, and the posterior inferior cerebellar artery (PICA) supplies the medial one-third of the lateral segment and entire medial segment. They also noted that in rare instances, the superior cerebellar artery also supply a branch to the flower basket of Bochdalek. In a series of 15 dissections, Sharifi et al. [15] found 
that in the majority of specimens, the lateral horizontal segment of the choroid plexus was supplied by the branches of the ipsilateral AICA (within the CP angle) while the medial horizontal, rostral and caudal sagittal segments are chiefly supplied by the branches of the ipsilateral PICA. Contralateral PICA and AICA may rarely supply branches to the medial horizontal, rostral and caudal sagittal segments [5]. Table 2 shows the arterial supply to the different segments of the choroid plexus of the fourth ventricle (Fig. 8).

The vein of the lateral recess of the fourth ventricle collects venous outflow from the choroid plexus and drains primarily cranially to reach the petrosal vein, which then drains into the superior petrosal sinus.

\section{Imaging}

Hayman et al. [4] have described overlapping scans in the orbital plane after contrast infusion as the best way to image the choroid plexus of the fourth ventricle on CT. Horsburgh et al. [6] investigated 100 individuals with normal pre- and post-contrast head CT scans and 100 individuals with normal post-contrast T1-weighted MR images. They classified Bochdalek's flower baskets based on shape (bulbous versus flat), lateral extension (prominent extension or full bouquet vs. moderate extension and symmetry as well as calcifications. On contrastenhanced MRIs, the flower baskets were bulbous in $54 \%$, flat in $40 \%$ or both in $6 \%$. Bilateral symmetry was notable in $80 \%$ of study individuals. The lateral extension was prominent in $96 \%$, moderate in $2 \%$ and slight in $2 \%$. The mean anteroposterior diameter of the flower baskets was $3.5 \mathrm{~mm}$. On CT scans, various degrees of calcification were found in $38 \%$ older than 51 years of age, with a heavy calcification in 6\%. Notable in this study was the relationship between the Bochdalek's flower baskets and vertebral artery. In 17 of 200 (8.5\%) individuals studied by contrast-enhanced images, the vertebral artery was in close proximity to the flower baskets, more on the left side than on the right owing to the tortuosity in the course of the left vertebral artery. Bochdalek's flower basket may give rise to a choroid plexus tumor in the cerebellopontine angle [7]. A flower basket with prominent bulbous appearance, asymmetry, calcification or heavy enhancement on the imaging may occasionally lead to misdiagnosis of aneurysm or cerebellopontine angle tumor [6]. 
On MRI and ultrasound, Mudhukar et al. [10] found the mean thickness of the choroid plexus of the fourth ventricle was $2.5 \mathrm{~mm}$ with the length of the lateral limb measuring $11.3 \mathrm{~mm}$. About 35\% of the time, Bradac et al. [1] identified the choroid plexus of the fourth ventricle on lateral vertebral angiograms.

\section{Conclusions}

A thorough understanding of the normal and variant anatomy of the fourth ventricular choroid plexus is necessary for those who operate or interpret imaging of this region. We identified variations of the choroid plexus of the fourth ventricle that to our knowledge, have not been previously reported. Knowledge of this anatomy will hopefully minimized misdiagnosis or confusion during surgical approaches to the fourth ventricle.

\section{References}

1. Bradac GB, Simon RS, Fiegler W, Schneider H (1976) A radioanatomical study of the choroid plexus of the fourth ventricle. Neuroradiology 31:87-91.

2. Colletti V, Fiorino FG, Carmer M, Giarbini N, Sacchetto L, Cumer G (2000) Am J Otol 21: 826-836.

3. Corrales M, Greitz T (1972) Fourth ventricle. I. Morphologic and radiologic investigation of the normal anatomy. Acta Radiol Diagn (Stockh). 12:113-33.

4. Hayman LA, Evans RA, Hinck VC (1979) Choroid plexus of the fourth ventricle: a useful CT landmark. Am J Roentgol 133:285-288. 
5. Hendrix P, Griessenauer CJ, Foreman P, Loukas M, Fisher WS, Rizk, Shoja MM, Tubbs RS (2014) Arterial supply of the lower cranial nerves: a comprehensive review. Clin Anat 27:108-117.

6. Horsburgh A, Kirollos RW, Massoud TF (2012) Bochdalek's flower basket: applied neuroimaging morphometry and variants of choroid plexus in the cerebellopontine angles. Neuroradiology 54:1341-6.

7. Jaiswal S, Vij M, Mehrotra A, Kumar B, Nair A, Jaiswal AK, Behari S, Jain VK (2013) Choroid plexus tumors: A clinico-pathological and neuro-radiological study of 23 cases. Asian J Neurosurg. 8:29-35.

8. Jordan HE (1920) A Textbook of Histology. New York: Appleton.

9. Lang J (1995) Skull base and related structures. Atlas of clinical anatomy. Stuttgart: Schattauer.

10. Madhukar M, Choudhary AK, Boal DK, Dias MS, Iantosca MR (2012) Choroid plexus: normal size criteria on neuroimaging. Surg Radiol Anat 34:887-95.

11. Matsushima T, Rhoton AL Jr, Lenkey C (1982) Microsurgery of the fourth ventricle: Part 1. Microsurgical anatomy. Neurosurgery 11:631-67.

12. O’Rahilly R, Müller F (1990) Ventricular system and choroid plexuses of the human brain during the embryonic period proper. Am J Anat 189:285-302.

13. Ozveren MF, Türe U, Ozek MM, Pamir MN (2003) Anatomic landmarks of the slossopharyngeal nerve: a microsurgical anatomic study. Neurosurgery 52:1400-1410.

14. Robinson A (1931) Cunningham's Textbook of Anatomy, $6^{\text {th }}$ edition. New York, Oxford University Press.

15. Sharifi M, Ciołkowski M, Krajewski P, Ciszek B (2005) The choroid plexus of the fourth ventricle and its arteries. Folia Morphol (Warsz). 64:194-8.

16. Shoja MM, Oyesiku NM, Shokouhi G, Griessenauer CJ, Chern JJ, Rizk EB, Loukas M, Miller JH, Tubbs RS (2014) A comprehensive review with potential significance during skull base and neck operations, Part II: glossopharyngeal, vagus, accessory, and hypoglossal nerves and cervical spinal nerves 1-4. Clin Anat 27:131-44.

17. Shoja MM, Oyesiku NM, Griessenauer CJ, Radcliff V, Loukas M, Chern JJ, Benninger B, Rozzelle CJ, Shokouhi G, Tubbs RS (2014) Anastomoses between lower cranial and upper cervical nerves: a comprehensive review with potential significance during skull 
base and neck operations, part I: trigeminal, facial, and vestibulocochlear nerves. Clin Anat 27:118-30.

18. Tubbs RS, Cesmebasi A, Loukas M, Hogan E, Kralovic S, Cohen-Gadol AA (2015) The Chiari malformations: a review with emphasis on anatomical traits. Clin Anat 28:184194.

\section{Figure Legends:}

Figure 1: Sagittal cadaveric view of the choroid plexus of the fourth ventricle (arrow).

Figure 2: T1-weighted sagittal MRI illustrating the choroid plexus of the fourth ventricle (arrow).

Figure 3: T2-weighted sagittal MRI illustrating the choroid plexus of the fourth ventricle (arrow).

Figure 4: Ventral surface of the brain with opened fourth ventricle. Note the typical appearance of the choroid plexus of the fourth ventricle with its midline attachment and extensions bilaterally into the foramina of Luschka.

Figure 5: Dorsal view of the exposed fourth ventricle. Note the typical extension of choroid plexus from the midline and laterally into the foramen of Luschka on the left (arrows) and lack of such an extension on the right side.

Figure 6: Dorsal view of the exposed fourth ventricle illustrating bilateral lack of extension of the choroid plexus into the foramina of Luschka.

Figure 7: Ventral view of the exposed fourth ventricle. Note the discontinuity between the midline choroid plexus (CP) and the laterally positioned choroid plexus (CP) leaving the left foramen of Luschka. The brackets encompass the foramen of Luschka.

Figure 8: Exposed roof of the fourth ventricle (pin exiting the foramen of Magendie) noting the inferior medullary velum with attached choroid plexus. This latex injected specimen (not part of the present study) illustrates the arterial supply of the choroid plexus of the fourth ventricle. Additionally, note that the midline choroid plexus does not have lateral extensions into the lateral recesses as seen in one of our studied specimens. 